\title{
Current Status, Economic importance and Management of Dodders (Cuscuta Spp) of Important Crops
}

\author{
Nagassa Dechassa* and Bayissa Regassa \\ Ethiopian Institute of Agricultural Research, Ambo Agricultural Research Centre, Ambo, Ethiopia
}

\begin{abstract}
Dodders (Cuscuta spp.) are one of the worst weeds that causes economic damage to economically valued crops. Cuscuta campestris, C. kilimanjari, C. reflexa, C. australis, C. suaveolens, C. hyalina, C. cassytoides, C. epilinum and C. planiflora are the most widespread Cuscuta species globally. Most of them are originated in North America and later distributed to many countries in the world. Coffea spp., Camellia sinensis, Glycine max, Allium cepa and Phaseolus spp. are the major hosts of the weed. Dodders are holoparasites, which lack chlorophyll and derive all their resources from their host and impose serious damage to their hosts. Cultural practices such as planting non-host cereal crops by removing host plants; regular monitoring and removal of new dodder weeds and mixed cropping of host crop with non-host crops is effective in managing the weed. Besides, biological control by use of parasitic fungi (Alternaria destruens, Fusarium tricinctum, Alternaria alternata, Geotrichum candidum and Alternaria spp and Colletotrichum gloeosporioides) play a role in managing the weed. In addition, chemical control with pre-emergence herbicides (pronamide, trifluralin and pendimethalin) and postemergence herbicides (pelargonic acid, imazamox, imazethapyr and paraquat) are effective to control dodders in many crops in extreme cases. Integrated use of herbicidal and mechanical control measures is effective in control, economically safe, socially acceptable and environmentally friendly than a single control measure. Moreover, host specific integrated Cuscuta Spp. management should be designed.
\end{abstract}

Keywords: Cuscuta campestris, Hautoria, Holoparasite, Parasitic weeds, Stem parasite

DOI: $10.7176 /$ ALST/87-04

Publication date: April $30^{\text {th }} 2021$

\section{Introduction}

Parasitic weeds are a major threat to native biodiversity, agricultural lands, range lands, national parks, road sides and urban green spaces with great economic and social consequences [1]. They rely on neighboring host plants to complete their life cycle, forming vascular connections through which they withdraw needed nutritive resources. They are the plants which attack other plants by making connections and deriving part or all of their food from the host. In natural ecosystems, parasitic plants form one component of the plant community and parasitism contributes to overall community balance. All forms of parasitic weeds, facultative or obligate parasites, hemiparasites or holoparasites, root parasites, or stem parasites interact with the host crop by means of the haustorium [2].

Among these species, the worst economic damage in important host crops is caused by species from only four genera: Cuscuta, Arceuthobium, Orobanche and Striga [3]. They are the most widely spreading and invading weeds in the world. The differences in yield losses caused by weeds varied from crop to crop and from region to region, in response to weed pressure, availability of control technology, cost of weed control and level of management practices [4].

Dodders are obligate holoparasites, typically exhibiting broad host ranges and impose serious damage to many crops. They are belonging to the family Convolvulaceae in older references and Cuscutaceae in the more recent publications. Over 200 species from the genus of Cuscuta are identified as obligate parasites that infect a wide range of important crop species [5]. Cuscuta campestris, C. kilimanjari, C. reflexa, C. australis, C. suaveolens, C. hyalina, C. cassytoides, C. epilinum and C. planiflora are considered the most widespread Cuscuta species globally [6]. The primary center of origin for dodder is North America and later widespread to many countries of all the continents (South America, Europe, Asia, Africa and Australia), except Antarctica [7]. Cuscuta species are the most frequently distributed in anthropogenic habitats in various types of crops in urban and rural areas [8]. Dodders are holoparasites, which lack chlorophyll and derive all their resources from their host. They commonly reduce the total biomass of the plant community [1].

Dodder weeds are known for many years and considered as minor weeds of few agricultural crops when they are first reported in many countries of the world. However, they are increasingly becoming an important parasitic weed of many field crops and horticultural crops worldwide. Therefore, the objective of this paper is to review the current status, economic importance and management practices of dodders.

\section{Body of The Text}

2.1. Origin and Distribution of Dodders

Dodders are considered the most widespread parasitic weeds globally. They are originated in North America 
and distributed to all the continents (South America, Europe, Asia, Africa and Australia) of the world except Antarctica [7]. The weed is cosmopolitan, most frequently distributed in anthropogenic habitats in various types of crops in urban and rural areas [9].

\subsection{Description and Life Cycle of Dodders}

Dodders are holoparasites, which lack chlorophyll and derive all their resources from their host. Their life cycle follows a systematic pattern that begins with seed germination and terminated with seed production. In the rainy season, dodder seeds germinate near the soil surface and send up slender, thread-like twisting stems varying in color from pale green to yellow or orange and without any cotyledons. The slender, leafless, thread-like stem sways slowly until it touches the stem of host plant and begins to wind around it (Figures 1a-c). On a host plant, the dodder stem immediately forms haustoria, which penetrate the stems so that dodder can extract its necessary growth requirements. Soon after attaching to a host plant, the lower end of the dodder withers and breaks its connection with the ground, while the upper part of the stem grows rapidly, often forming dense, stringy masses. However, if the dodder seedlings are unable to make physical contact with a susceptible host plant soon after germination, they will not survive.

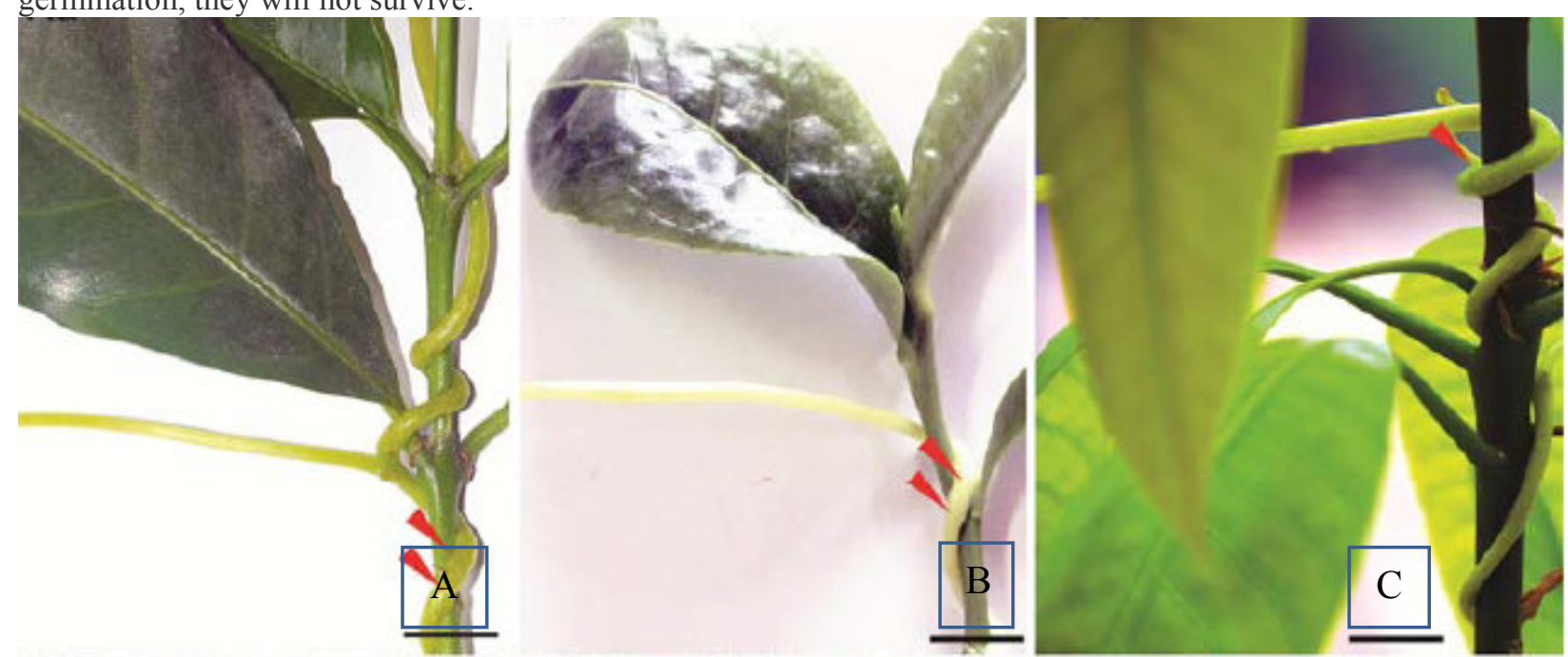

Figure 1. Dodder parasitism and extent of ingression into host plants A) Coffee B) Tea and C) Mango

Due to a limited amount of food reserves in their small seeds, seedlings must attach to an appropriate host within 3-5 days of germination [10], and establish vascular bundle connections that act as a conduit for siphoning water, nutrients and photo-assimilates. Thereafter, the parasite develops flowers and eventually produces viable seeds that shed back to the soil [11]. At this point, the host succumbs to parasitism often leading to its death.

\subsection{Host Range of Dodders}

Dodders are considered as a wide spreading and having a very wide hosts ranging from annual plants to perennial woody tree crops, which are extremely difficult to control and result in significant economic losses [3]; [12]. They are reported by several workers occurring in mild to severe form on a variety of hosts belonging to the most diverse families of annual and perennial plants. Up to a date about twenty-six (26) host plant species across 13 angiosperm orders, are parasitized by the dodders.

Perennial legume crops (Chickpea, Alfalfa, Clover, Beans, Pea, Lucerne, Lentil, Sesame, Blackgram, greengram, pegionpea, soybean and Berseem), vegetable nurseries (Tomato, Eggplant, Sweet Pepper, Potato, Cabsicum, Tomato, Carrot, Onion and Cabbage) and some other crop grown in plastic greenhouses are generally the preferred hosts of this parasitic flowering species [3]. The study also revealed that tree crops of agricultural values host range to tree crops of agricultural value Tea, Coffee, Citrus Spp, Sugarbeet, Cranberry, Blueberry and Mango are hosts for Cuscuta Spp. [12]. Non-crop hosts included Solanum spp., Rumex spp. and Senecio vulgaris [13]; [14]; [15]; [16]. 

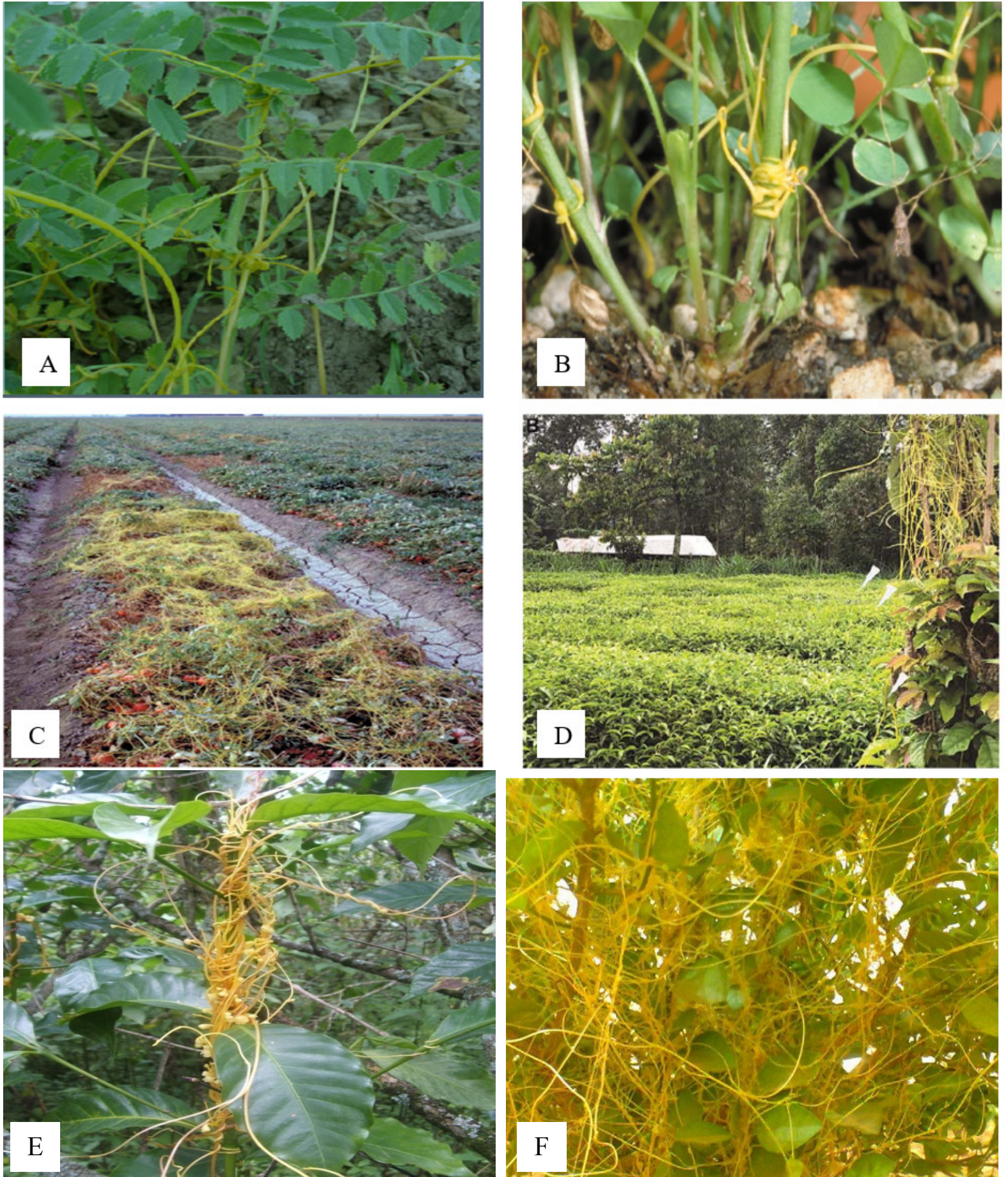

Figure 2. Cuscuta threat on A. Chick pea, B. Alfalfa, C. Tomato, D. Tea, E. Coffee, F. Citrus

\subsection{Parasitism of Dodders}

Dodders are obligate parasitic weed consisting of orange to yellow twining stems that produce small clusters of white flowers. The stems will wrap around the host plant and insert haustoria into the vascular system of the host and become a strong sink for photosynthates. Dodders and their hosts have symbiotic relationship in which dodders obtain their nutrients directly from a host plant. This has a detrimental effect on the host, but benefits the dodders. Although parasitic weeds are commonly known to lack chlorophyll, some species have green organs, making them partially photoautotrophic. The physical link between the parasitic dodders and their hosts is haustorium and often occurs through xylem-to-xylem attachment [17]. The parasite often maintains open or partially open stomata, allowing transpiration to aid in extracting nutrients from the host [18]. 


\subsection{Economic Importance Dodders}

Dodders are an obligate shoot parasite weeds causing growth inhibition and yields losses of many agricultural crops worldwide [19]. The wide host range of dodders and their wide geographical distribution, make them amongst the most damaging parasitic weeds worldwide [20]. Studies indicated that field dodders infestation reduced tomato yield by 50 to $75 \%$ [21], carrot yield by 70 to $90 \%$ [22], alfalfa forage and seed production by more than 50\% [23]. Dodder is also considered a troublesome weed in onion (Allium cepa), Bean (Phaseolus spp.), soybean (Glycine max), Ornamental shrubs, trees and groundcovers. Another study also revealed that the yield reductions due to Cuscuta spp ranging from 60 to $65 \%$ in chillies [24], 31 to $34 \%$ in greengram/blackgram [25], 60 to $65 \%$ in niger, $87 \%$ in lentil, $86 \%$ in chickpea, $72 \%$ in tomato and 60 to $70 \%$ in alfalfa depending upon its intensity of infestation [25]. Onion fields heavily infested with dodders should be destroyed, as there is no selective herbicide to control it available for this crop [26]. The weakened state of the infected plants does predispose them to loss from other maladies (disease, insect, and nematode invasions).

\subsection{Management Practices of Dodders}

Dodder weeds has been known in many field and horticultural crops in many countries for many years [12]; [27]; [3] and many studies have been conducted on its management since the potential threat of the weed to crops production. The weeds are widespread on many crops with high rates of infestation globally. This is due to the fact that many farmers have limited knowledge about the weed and were therefore indifferent towards its control resulting in increasing weed infestation [12]; [28]; [3]. It is also extremely difficult to achieve effective control of Cuscuta because of two reasons. 1) its seeds have a hard seed coat, can persist viable in soil for many years and continue to germinate and emerge throughout the year and 2) the nature of attachment and association between host and parasite requires a highly selective herbicide to destroy the parasite without crop damage. However, different management practices reducing the weed population and increasing crop yield are reviewed.

\subsubsection{Cultural Control}

dodders can be effectively managed by planting non-host cereal crops such as Maize, sorghum, winter wheat, broccoli and pecan. However, host plants should be controlled as part of a successful dodder management strategy. Besides, due to the longevity of dodder seed, once a host crop is planted in fields need to be monitored regularly, and new dodder Plants must be removed immediately. Mixed cropping of host crop (soybean) with non-host crops (maize) reduced $60 \%$ of Cuscuta infestation [29]. Since Cuscuta is very sensitive to shade, the shade from dense crop foliage suppresses Cuscuta significantly to control it almost completely [30].

\subsubsection{Mechanical Control}

Hand-pulling drying and burning of individual dodder before it produces any seed in newly infected fields can destroy the weed. This control measure should be done prior to dodder's attachment to the host plant [30].

\subsubsection{Chemical Control}

Several post-emergence and pre-emergence herbicides are effective for Cuscuta Spp suppression in sever infestation [31]; [22]. But, the nature of attachment and association between the parasitic weeds and host plants require a highly selective herbicide to control the parasite without crop damage. Application of pre-emergence herbicides prior to dodder emergence is common in controlling dodder. These include Kerb (pronamide), Treflan (trifluralin), and Prowl (pendimethalin) [31]; [32]; [33]. Whereas applications of post-emergence herbicides such as Dacthal (DCPA), Scythe (pelargonic Acid), Raptor (imazamox), Pursuit (imazethapyr) and Gramoxone (paraquat) are effective in dodder control [22]. Application of Roundup (Glyphosate) can also play a role in controlling of dodder; however, spot treatments of roundup will result in crop injury in non-Roundup Ready crops [28].

\subsubsection{Biological Control}

Research findings indicated that Alternaria destruens reduced C. gronovii infestation by $90 \%$ in cranberry (Vaccinium macrocarpon) and carrot (Daucus carota) [10]. Other fungi species such as Fusarium tricinctum, Alternaria alternata, Geotrichum candidum and Alternaria spp. are also identified that they are effective in managing Cuscuta gronovii and Cuscuta pentagona [34]. Also conidia suspension of Colletotrichum gloeosporioides has provided selective control of C. chinensis and C. australis in soybeans [34]; [35].

\subsubsection{Integrated Dodders Management}

Cook [36], concluded that an integrated use of biological control agent (Alternaria destruens), herbicides (glyphosate and ammonium sulfate) to control dodders is effective of as compared to a single control measures.

\section{Conclusions}

Dodders are among serious parasitic weeds of many crops worldwide. They are stem holoparasities and rely on host plants to complete their life cycle, forming vascular connections through which they withdraw needed nutritive resources. Cuscuta campestris, C. kilimanjari, C. reflexa, C. australis, C. suaveolens, C. hyalina, C. cassytoides, C. epilinum and C. planiflora are the most wide spreading among 200 Cuscuta species. Chickpea, alfalfa, clover, beans, pea, lucerne, lentil, sesame, blackgram, greengram, pegionpea, soybean, berseem, tomato, 
eggplant, sweet pepper, potato, cabsicum, tomato, carrot, onion, cabbage, tea, coffee, citrus Spp, sugarbeet, cranberry, blueberry and mango are hosts for Cuscuta Spp. They cause drastic crop yield losses.

The dodders' seed persistence in the soil for long period of time, ways of reproduction, ability to adapt to wide range of climatic conditions, nature of attachment to the hosts and association between host and parasite made their management difficulty.

However, crop rotation, mixed cropping of host crops with non-host crops, hand-pulling drying and burning of individual dodder before it produces any seed in newly infected fields are effective in controlling the weed in small areas. Use of biological control agents; parasitic fungi (Alternaria destruens, Fusarium tricinctum, Alternaria alternata, Geotrichum candidum and Alternaria spp and Colletotrichum gloeosporioides) play a role in controlling the weed at experimental level. In addition, chemical control with pre-emergence herbicides (pronamide, trifluralin and pendimethalin) and post-emergence herbicides (pelargonic acid, imazamox, imazethapyr and paraquat) are effective to control dodders in many crops in extreme cases. Integrated use of herbicidal and mechanical control measures is effective in control, economically safe, socially acceptable and environmentally friendly than a single control measure. Moreover, host specific integrated dodder management should be designed.

\section{The Way Forward}

Since the present status of dodders are remarkably on increasing trend, it is recommended to: -

1) Create awareness among the farmers about the biology, ways of spread, economic importance and management options of the weed.

2) Detect and monitor early since they are critical for the management of weed, as successful eradication or suppression is only possible when infestations are small.

3) Search for more improved or alternative approaches in managing the weed.

4) Develop integrated dodder management mechanisms instead of using a single method.

\section{References}

1. Press, M.C. and G.K. Phoenix, Impacts of parasitic plants on natural communities. New phytologist, 2005. 166(3): p. 737-751.

2. Riopel, J. and M. Timko, Haustorial initiation and differentiation. Parasitic plants, 1995. 39: p. 79.

3. Sarić-Krsmanović, M., Field Dodder: Life Cycle and Interaction with Host Plants. Co-Evolution of Secondary Metabolites, 2020: p. 101-120.

4. Runyon, J.B., et al., Parasitism by Cuscuta pentagona sequentially induces JA and SA defence pathways in tomato. Plant, cell \& environment, 2010. 33(2): p. 290-303.

5. Kaiser, B., et al., Parasitic plants of the genus Cuscuta and their interaction with susceptible and resistant host plants. Frontiers in plant science, 2015. 6: p. 45.

6. Yuncker, T.G., The genus Cuscuta. Memoirs of the Torrey Botanical Club, 1932. 18(2): p. 109-331.

7. Holm, L., et al., World weeds: natural histories and distribution. 1997: John Wiley \& Sons.

8. Fanfarillo, E., et al., The segetal flora of winter cereals and allied crops in Italy: Species inventory with chorological, structural and ecological features. Plant Biosystems-An International Journal Dealing with all Aspects of Plant Biology, 2020. 154(6): p. 935-946.

9. Salama, F., et al., Weed flora of common crops in desert reclaimed arable lands of southern Egypt. Taeckholmia, 2016. 36(1): p. 58-76.

10. Lanini, W. and M. Kogan, Biology and management of Cuscuta in crops. International Journal of Agriculture and Natural Resources, 2005. 32(3): p. 127-141.

11. Nickrent, D.L. and L.J. Musselman, Introduction to parasitic flowering plants. The Plant health instructor, 2004. 13(6): p. 300-315.

12. Masanga, J., et al., Physiological and ecological warnings that Dodder pose an exigent threat to farmlands in Eastern Africa. bioRxiv, 2020.

13. Barath, K. and J. Csiky, Host range and host choice of Cuscuta species in Hungary. Acta Botanica Croatica, 2012. 71(2): p. 215-227.

14. Jayasinghe, C., et al., Cuscuta species in the lowlands of Sri Lanka, their host range and host-parasite association. 2004

15. Costea, M., M.A. Wright, and S. Stefanović, Untangling the systematics of salt marsh dodders: Cuscuta pacifica a new segregate species from Cuscuta salina (Convolvulaceae). Systematic Botany, 2009. 34(4): $\mathrm{p}$ 787-795.

16. Roney, J.K., P.A. Khatibi, and J.H. Westwood, Cross-species translocation of $m R N A$ from host plants into the parasitic plant dodder. Plant Physiology, 2007. 143(2): p. 1037-1043.

17. Kuijt, J., Haustoria of phanerogamic parasites. Annual Review of Phytopathology, 1977. 15(1): p. 91-118.

18. Westwood, J.H., The physiology of the established parasite-host association, in Parasitic Orobanchaceae. 
2013, Springer. p. 87-114.

19. Mushagalusa, N., et al., Cuscuta campestris yunker, a dangerous obligate parasitic weed observed in cassava crop in the eastern part of the Democratic Republic of Congo. African Journal of Agricultural Research, 2016. 11(22): p. 1980-1983.

20. Parker, C., Parasitic weeds: a world challenge. Weed Science, 2012. 60(2): p. 269-276.

21. Goldwasser, Y., M.R.M. Sazo, and W.T. Lanini, Control of field dodder (Cuscuta campestris) parasitizing tomato with ALS-inhibiting herbicides. Weed Technology, 2012: p. 740-746.

22. Bewick, T.A., L.K. Binning, and M.N. Dana, Postattachment control of swamp dodder (Cuscuta gronovii) in cranberry (Vaccinium macrocarpon) and carrot (Daucus carota). Weed Technology, 1988: p. 166-169.

23. Cudney, D., S. Orloff, and J. Reints, An integrated weed management procedure for the control of dodder (Cuscuta indecora) in alfalfa (Medicago sativa). Weed Technology, 1992: p. 603-606.

24. Mukhtar, I., I. Khokhar, and S. Mushtaq, Cuscuta campestris Yunck., ANew PEST OF Capsicum. Pak. J. Weed Sci. Res, 2011. 17(1): p. 103-110.

25. Kaliyadasa, E. and S.L. Jayasinghe, Screening of allelopathic activity of common weed species occurring in agricultural fields. African Journal of Agricultural Research, 2018. 13(47): p. 2708-2715.

26. Mishra, J., et al., Relative tolerance of rainy season crops to field dodder (Cuscuta campestris) and its management in niger (Guizotia abyssinica). Crop Protection, 2007. 26(4): p. 625-629.

27. Bhat, N.A., et al., First observation of field dodder and its host range in Meghalaya. Indian Journal of Weed Science, 2018. 50(2): p. 192-194.

28. Cook, J.C., et al., Effects of Alternaria destruens, glyphosate, and ammonium sulfate individually and integrated for control of dodder (Cuscuta pentagona). Weed technology, 2009. 23(4): p. 550-555.

29. Mishra, J., B. Moorthy, and A. Gogoi, Biology and management of Cuscuta. 2006: Director, National Research Centre for Weed Science.

30. Mishra, J., Biology and management of Cuscuta species. Indian Journal of Weed Science, 2009. 41(1-2): p. $1-11$

31. Kumar, N., et al., Prospects and potential of post-emergence herbicides for weed management in pulses. Pulses: Challenges \& Opportunities: p. 199.

32. Orloff, S. and B. Tickes, Weed Management in Alfalfa: Where We've Been and Where We're Going. 2014.

33. Parker, C., Protection of crops against parasitic weeds. Crop protection, 1991. 10(1): p. 6-22.

34. Aliyas, I.M., M.A. Ahmed, and M.Y. Ali, Germination response of dodder seeds with some agricultural crops seeds in laboratory conditions. crops, 2013. 20.

35. Saric-Krsmanovic, M. and S. Vrbnicanin, Field dodder-How to control it? 2015.

36. Cook, J.C., Integrated control of dodder (Cuscuta pentagona Engelm.) using glyphosate, ammonium sulfate, and the biological control agent Alternaria destruens Simmons, sp. nov. 2006: University of Florida. 